\title{
PENGURANGAN PEMBOROSAN WAKTU PRODUKSI PADA PROSES PEMBUATAN RUMAH BONEKA MENGGUNAKAN PENDEKATAN LEAN
}

\author{
TIARA \\ Program Studi Teknik Industri \\ Fakultas Teknik, dan Ilmu Komputer \\ Universitas Indraprasta PGRI \\ Email: tiaramardi.04@gmail.com
}

\begin{abstract}
Abstrak. CV. Rumah boneka adalah perusahaan industri kecil menengah dan manufaktur, memproduksi rumah boneka dengan bahan dasar kayu. Penelitian ini bertujuan mengetahui jenis pemborosan waktu produksi pada setiap proses dan memberikan usulan perbaikan sehingga dapat meningkatkan produktivitas waktu produksi rumah boneka. Penelitian ini menggunakan metode kuantitatif melalui pendekatan lean dengan tools value stream mapping (VSM), pada awal penelitian, dilakukan penggambaran current state mapping yang didapat dari observasi pada CV. Rumah boneka, kemudian dilakukan identifikasi masalah dari masing-masing proses produksi. Kemudian dilakukan analisa masalah menggunakan line balancing untuk meratakan waktu siklus. Pada current state mapping waktu proses produksi sebesar 1418,76 dengan lead time 10 hari. Berdasarkan analisa, beberapa penyebab yang dapat menimbulkan waste yaitu: keterlambatan kedatangan bahan baku, faktor fisik pekerja, pekerja yang tidak mengikuti standar kerja CV.rumah boneka dan gerakan yang tidak diperlukan tetapi dilakukan pekerja.
\end{abstract}

Kata Kunci : fishbone diagram, lead time, , line balancing, value stream mapping, waste

Abstract. CV. Puppet house is a small and medium-sized industrial enterprise and manufactures in producing doll house with wood base material. The purpose of this study is to know the kind of wasted production time on each production process at CV. Puppet house and give repair suggestions so as to increase the productivity of puppet house production time. This study uses a quantitative approach with the processing time of each workstation. This study uses a lean approach with tools value stream mapping (VSM), at the beginning of the study, drawing a current state mapping obtained from observations on puppets $C V$, then from the image was identified problem of each production process. Then analyze the problem using line balancing to level the cycle time, fishbone diagram to find out the factors causing the problem of the production of puppets and the introduction of waste on each production process. In the current state mapping the spend time of 1418.76 with 10 day lead time. After calculating and equating cycle time by using line balancing. Based on the analysis, there are several causes that can cause waste among others: delay of raw material arrival, physical factors of workers, workers who do not follow the work standards determined by the puppets and movements that are not required but performed by the workers. The proposed repair can be given to the $C V$ of these puppets is to communicate well with the supplier, to conduct training once every 3 months to the employees, providing a special place for storage of raw materials and semi-finished materials and do not turn on television while working.

Keywords: Lean Manufacturing, Waste, Value Stream Mapping, Lead Time, Fshbone Diagram, CV. Rumah boneka. 


\section{PENDAHULUAN}

CV. Rumah boneka yang terletak di Jln. Rs. Fatmawati, Jakarta Selatan adalah perusahaan industri kecil menengah dan manufaktur dalam memproduksi rumah boneka dengan bahan dasar dari kayu. Usaha pembuatan rumah boneka ini memperoleh bahan baku dari beberapa toko bangunan yang berada disekitar CV. Rumah boneka. Sistem produksi yang diterapkan oleh CV. Rumah boneka adalah make to order dimana perusahaan memproduksi rumah boneka sesuai dengan pesanan konsumen. Dalam hal ini, konsumen juga diperbolehkan untuk memesan rumah boneka sesuai dengan model, warna, dan ukuran yang diinginkan konsumen (customer).

Dalam hal produksinya, rumah boneka pada CV. Rumah boneka dilakukan oleh beberapa pekerja yang sebagian besar memiliki kecacatan fisik. Hal ini tentunya akan menjadikan tantangan tersendiri bagi manajemen CV. Rumah boneka. Pada CV. Rumah boneka teknik yang digunakan untuk memproduksi rumah boneka ini masih sederhana, yaitu dengan menggunakan peralatan manual, beberapa mesin yang digunakan untuk proses produksi yaitu, mesin potong, bor dan amplas.

Selain itu pada cv. ini ada beberapa pekerja yang memiliki kecacatan fisik, jumlah pekerja yang sedikit dan posisi kerja yang tidak ergonomis diduga menjadi penyebab proses produksi berlangsung dalam waktu lama atau lead time produksi yang terlalu panjang. Kondisi-kondisi tersebut dapat mengakibatkan pemborosan baik dalam waktu produksi maupun dalam penggunaan energi pekerja. Menurut Heizer dan Render (2009), Pemborosan terjadi pada proses bisnis pabrik yang sering ditemukan seperti produk cacat, kelebihan persediaan, pemborosan waktu dan sebagainya. Hal tersebut dapat mengakibatkan penurunan performansi perusahaan dan terjadinya pemborosan lantai produksi.

Dapat disimpulkan bahwa pemborosan dapat terjadi dimana saja, karena pemborosan tidak dapat terlihat sehingga banyak pabrik mengalami pemborosan dengan pemborosan waktu yang tanpa disadari, produk cacat menyebabkan pemborosan, menunggu waktu, produksi berlebihan, pemborosan inventory dan sebagainya. Untuk mengatasi masalah tersebut maka pada penelitian ini menggunakan Lean.

Menurut Gaspersz dan Fontana (2011), menjelaskan Lean adalah suatu upaya terus-menerus (continous improvement efforts) untuk menghilangkan pemborosan (waste), dan untuk meningkatkan nilai tambah (value added) produk (barang dan atau jasa), agar memberikan hasil kepada pelanggan (customer value).

\section{METODE}

Penelitian ini menggunakan metode penelitian kuantitatif, diawali dengan melakukan pengamatan bagian produksi rumah boneka pada CV. Rumah boneka. Setelah dilakukan pengamatan dan kegiatan wawancara secara langsung kepada para pekerja yang bersangkutan pada bagian produksi ditemukan beberapa pemborosan waktu produksi pada masing-masing stasiun kerja di CV.Rumah boneka. Desain penelitian yang digunakan dalam penelitian ini adalah menggunakan penelitian deskriptif karena menggambarkan keadaan suatu proses sebelum produksi.

Pengolahan data pada penelitian ini menggunakan line balancing untuk mengurangi kemacetan produksi masing-masing stasiun kerja. Perhitungan line balancing menggunakan rumus-rumus killbridge western, sebagai berikut:

1. Perhitungan Waktu Siklus (Ws)

$$
\mathrm{Ws}=\frac{\text { Jam kerja }}{\text { Demand }}
$$

2. Perhitungan jumlah stasiun krja

$$
\text { Jumlah satsiun kerja }=\Sigma \text { waktu tugas }
$$


3. Lintasan Efisiensi (LE)

Ws

$$
\mathrm{LE}=\frac{\Sigma \mathrm{ST} \times 100 \%}{\mathrm{~K} \times \mathrm{CT}}
$$

4. Minimasi Smoothness Index

$$
\mathrm{SI}=\sqrt{ } \Sigma(\mathrm{ST} \max -\mathrm{STI})^{2}
$$

5. Delay Time (DT)

$$
\mathrm{DT}=\mathrm{k} \times \mathrm{ST} \max -\Sigma \mathrm{STI}
$$

6. . Persentasi Waktu Menganggur (\%DT)

$$
\% \mathrm{DT}=\frac{\mathrm{DT} \times 100 \%}{\mathrm{k} \times \mathrm{ST} \operatorname{Max}}
$$

7. Efisiensi Stasiun Kerja (ESK)

$$
\text { ESK } \mathrm{i}=\frac{\mathrm{ST} \mathrm{I} \times 100 \%}{\mathrm{ST} \max }
$$

Pengolahan data selanjutnya dengan melakukan perhitungan Value added ratio (VAR), dengan menggunakan rumus sebagai berikut:

$$
\mathrm{VAR}=\frac{\mathrm{VA}}{\mathrm{NVA}+\mathrm{VA}} \times 100 \%
$$

Pengolahan data selanjutnya yaitu perhitungan takt time, dengan menggunakan rumus sebagai berikut:

$$
\text { Takt Time }=\frac{\text { Available working time per day }}{\text { Customer demand rate per day }}
$$

Setelah dilakukan pengolahan data menggunakan perhitungan line balancing, value added ratio (VAR) dan takttime, amak langkah selanjutnya yaitu melakukan analisa menggunakan fishbone diagram untuk mengetahui akar penyebab masalah produksi rumah boneka.

\section{HASIL DAN PEMBAHASAN}

CV. Rumah Boneka ini berada didalam lindungan Yayasan Wisma Cheshire (YWC), Yayasan Wisma Cheshire (YWC) merupakan sebuah yayasan yang terdaftar di Indonesia. Yayasan yang berada di Jakarta ini telah dibuka sejak November 1974 oleh Grup Captain Leonard Cheshire, VC. Berikut proses produksi Rumah Boneka dapat dilihat pada Gambar 1. 


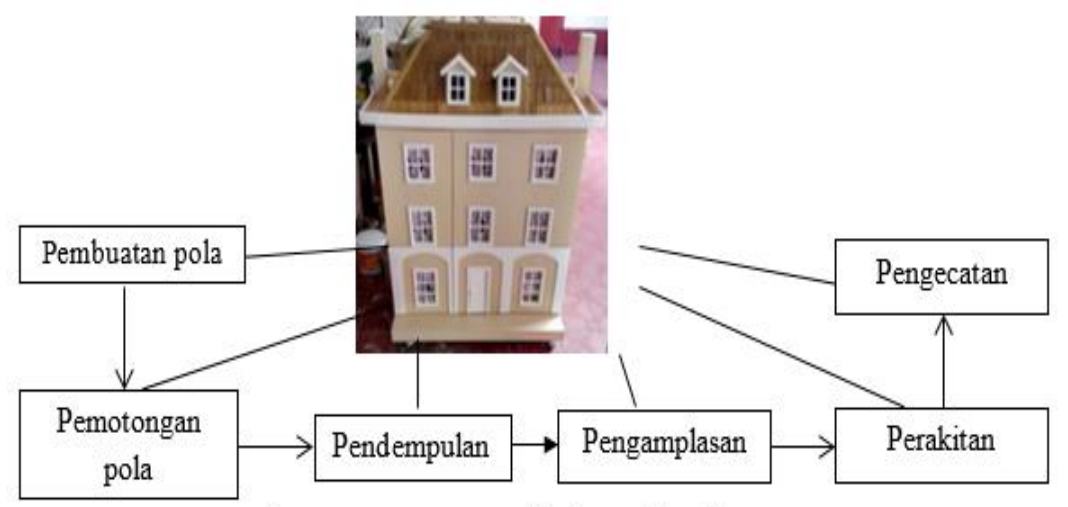

Gambar 1. Proses umum produksi rumah boneka

Data inventory (persediaan material, WIP dan finished good) yang berada antara stasiun kerja pada satuan waktu tertentu dapat dilihat pada Tabel 1.

Tabel 1. Jumlah Inventory (bahan baku, WIP dan finished good)

\begin{tabular}{clc}
\hline Status produk & \multicolumn{1}{c}{ Stasiun kerja } & Jumlah (Day) \\
Bahan baku & Gudang/Supplier & 2 \\
WIP & Pembuatan pola & 2 \\
WIP & Pemotongan pola & 1 \\
WIP & Pendempulan & 0 \\
WIP & Pengamplasan & 0 \\
WIP & Perakitan & 2 \\
WIP & Pengecatan & 2 \\
Barang jadi & Shipping & 1 \\
$\Sigma \mathrm{x}$ & & 10 Hari \\
\hline
\end{tabular}

Faktor-faktor yang mempengaruhi pada masalah jumlah inventory yang besar ini dapat dilihat Fishbone Diagram pada Gambar 2. 


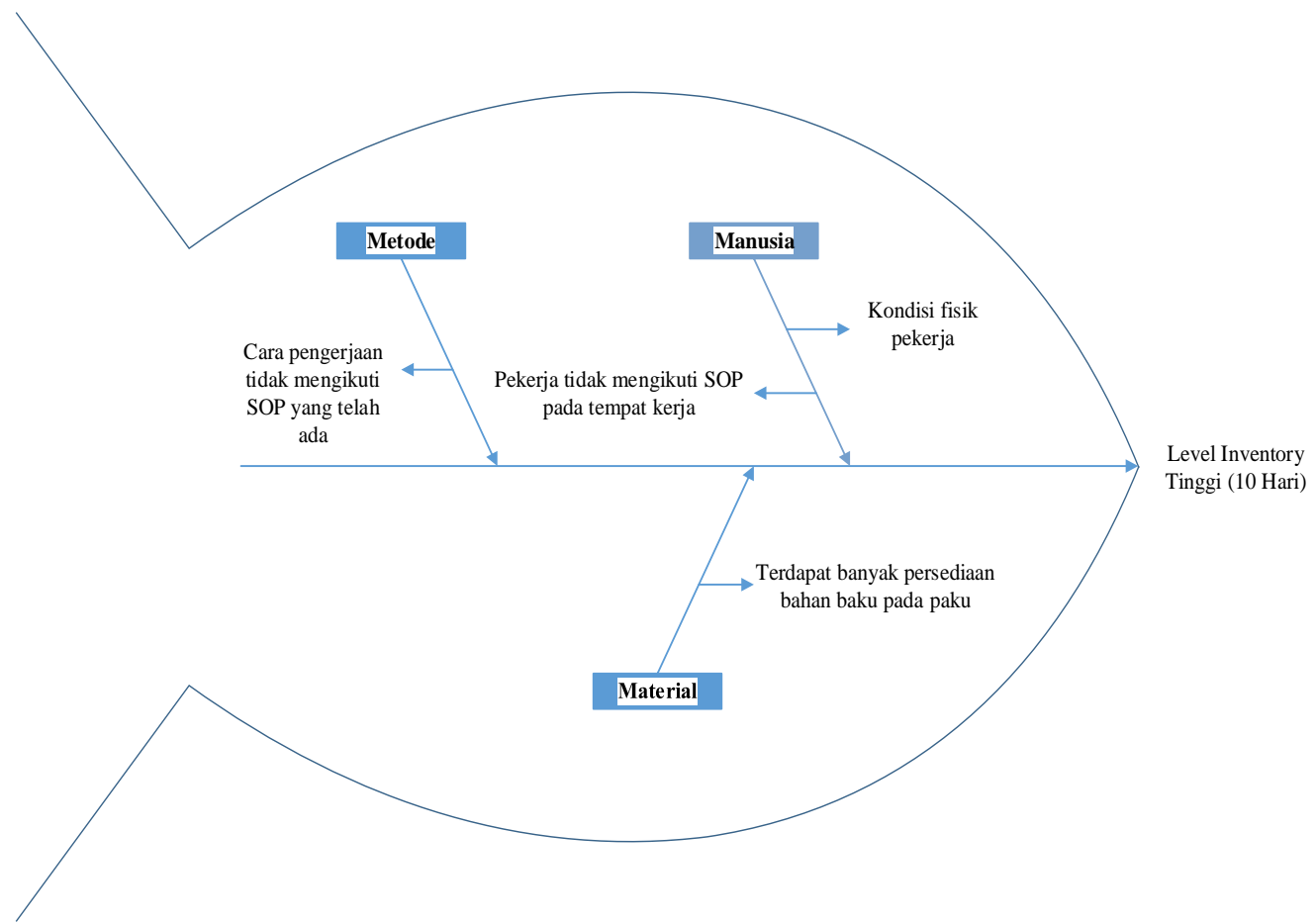

Gambar 2. Fishbone Diagram pada jumlah Inventory Produksi Rumah Boneka

Jenis Pemborosan Pada Produksi Rumah Boneka

Pada CV.Rumah boneka terdapat beberapa orang pekerja mengalami cacat fisik, hal ini dapat mengurangi kecepatan dalam bekerja dan pekerja tersebut juga memiliki kendala yaitu gerak yang terbatas karena kondisi fisik yang dialaminya. Berdasarkan kondisi actual CV.RB tersebut maka dapat disimpulkan beberapa jenis pemborosan yang terjadi di CV.RB, antara lain: inventory, processing, motion dan waiting.

Jenis pemborosan pertama yang terdapat pada CV.RB yaitu inventory, dengan adanya pengerjaan yang lama disepanjang produksi rumah boneka menyebabkan level inventory tinggi. Untuk jumlah inventory yang panjang pada masing-masing stasiun kerja dapat dilihat pada table 1 . Jenis pemborosan kedua yaitu processing, pada CV.RB ini pekerja sering melakukan kesalahan dalam proses produksi pada stasiun kerja perakitan pola. Pekerja sering salah dalam merakit antara 2 komponen, dikarenakan pekerja kurang teliti dalam melihat ukuran yang telah ditandai sebelumnya.

Jenis pemborosan ketiga yaitu, motion (gerakan), pekerja sering kali dan hampir setiap saat melakukan gerakan yang tidak memberikan nilai tambah untuk produksi rumah boneka tersebut. Gerakan-gerakan yang dilakukan seperti: mencari pensil dan komponen. Mondar mandir mencari alat yang akan digunakan untuk produksi. Jenis pemborosan keempat yaitu menunggu (waiting), pemborosan ini terjadi pada stasiun kerja pengamplasan, perakitan dan pengecatan. Pada stasiun kerja pendempulan, setelah pekerja selesai dalam melakukan aktivitasnya pekerja pada stasiun kerja pengamplasan tidak langsung melakukan aktivitasnya, akan tetapi pekerja pada sttasiun kerja pengamplasan menunggu komponen yang di dempul kering terlebih dahulu.

Selanjutnya stasiun kerja pertakitan, pada stasiun kerja perakitan ini proses penggabungan 2 komponen tidak hanya menggunakan paku, akan tetapi pada proses ini juga menggunakan lem untuk menggabungan kedua komponen. Pekerja pada proses pengecatan harus menunggu proses penggabungan atau perakitan komponen tersebut kering terlebih dahulu. 


\section{Penggambaran Current State Mapping}

Proses pembuatan current state mapping terdiri dari enam langkah (Nielsen, 2008). Langkahlangkahnya adalah sebagai berikut:

1. Menentukan product family

Penentuan product family dilakukan apabila terdapat banyak jenis produk. Pemilihan product family berdasarkan kesamaan rute, waktu proses, dan rata-rata permintaan konsumen.

2. Menentukan tujuan perbaikan

Kondisi sekarang dapat dipetakan dengan menentukan tujuan terlebih dahulu. Tujuan yang ingin dicapai misalnya mengurangi biaya dengan mengeliminasi waste atau melakukan produksi dengan tepat waktu sesuai permintaan konsumen.

3. Membentuk tim value stream mapping

4. Mengikuti aliran

Mengikuti aliran berarti berkeliling di tempat produksi untuk melihat dan memahami setiap proses.

5. Mengerti customer value and scheduling

Value stream mapping memiliki tujuan untuk memberikan produk yang tepat dengan waktu yang tepat dan harga yang tepat pada customer. Menjadwalkan segala proses pada value stream mapping berguna untuk mengetahui material bahan baku yang digunakan sehingga dapat melakukan pemesanan jika bahan baku memiliki stock material yang terbatas.

6. Menggambarkan current state map

Current state map dapat digambarkan dengan mengumpulkan data operasi kerja dan antrian dalam sebuah pekerjaan, material yang digunakan, dan aliran proses dari operasi kerja satu dengan operasi kerja yang lainnya.

Dengan adanya penggambaran current state mapping akan mempermudah untuk mengetahui gambaran umum mengenai alur produksi rumah boneka. Pada current state mapping ini mulai dari order pelanggan, pemesanan bahan baku sampai ke pengiriman finish good kepada pelanggan dan juga dapat memfokuskan kepada proses perbaikan waktu produksi. Current state mapping pada CV. Rumah Boneka dapat dilihat pada Gambar 3. 


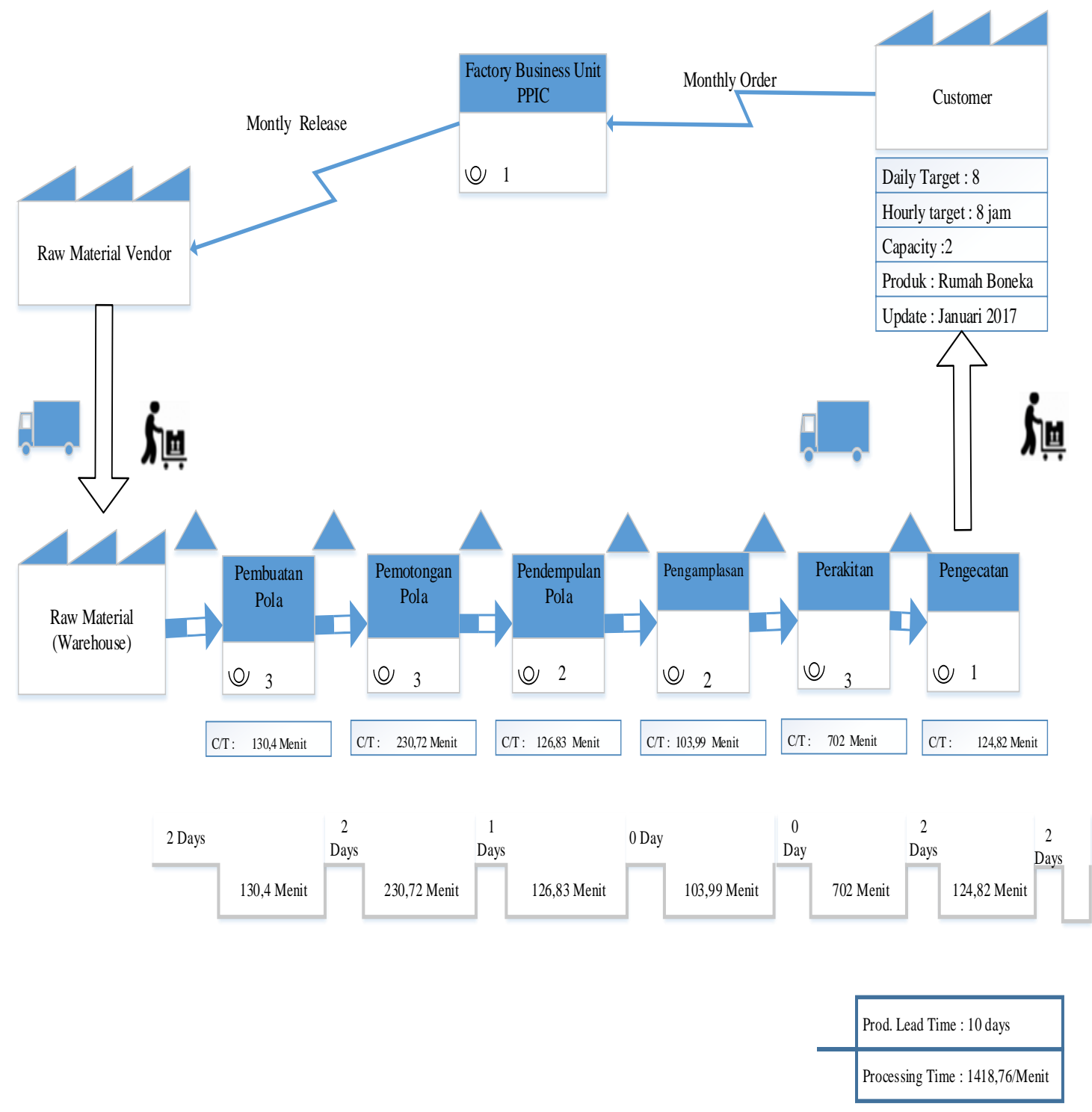

Gambar 3. Current State Mapping CV. Rumah Boneka

\section{Pemerataaan Waktu Siklus Menggunakan Line Balancing}

Pada penelitian ini menggunakan line balancing dengan metode killbridge western. Killbridge western adalah metode yang dirancang oleh M.Kilbridge dan L.Wester sebagai pendekatan untuk mengatasi masalah keseimbangan lini, pada metode ini, dilakukan pengelompokkan task-task ke dalam sejumlah kelompok yang mempunyai tingkat keterhubungan yang sama (Halim, 2003). Perhitungan line balancing dengan metode killbridge western menggunakan satuan menit. Presedence diagram produksi rumah boneka dapat dilihat pada Gambar 4.

\section{Precedence Diagram}




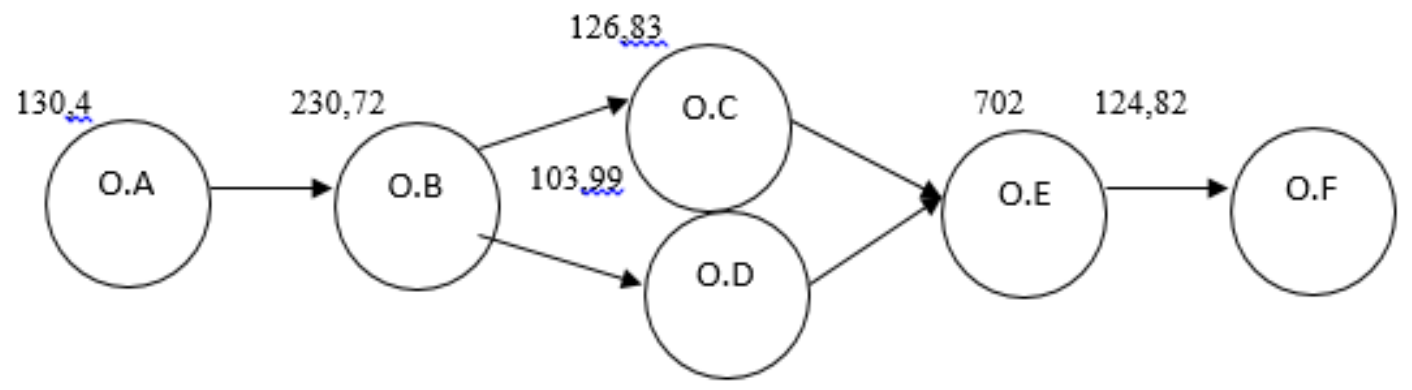

Gambar 4. Precedence Diagram Produksi Rumah Boneka

Keterangan: (Operasi A = Proses Pembuatan Pola, Operasi B = Proses Pemotongan Pola, Operasi C $=$ Proses Pendempulan Operasi $\mathrm{D}=$ Proses Pengamplasan, Operasi $\mathrm{E}=$ Proses Perakitan, Operasi $\mathrm{F}$ $=$ Proses Pengecatan).

\section{Perhitungan Waktu Siklus (Ws)}

Diketahui : - Demand : 8 unit/bulan - Jam kerja : 2,5 jam/hari (dalam sebulan 20 hari kerja)

Penyelesaian: $\mathrm{Ws}=2,5$ jam x $20=50=6,25 \mathrm{Jam} / \mathrm{Hari}=375 \mathrm{Menit} / \mathrm{hari}$

$$
8 \quad 8
$$

3. Perhitungan Jumlah stasiun kerja

Jumlah stasiun kerja $=\underline{\Sigma \text { waktu tugas (rumah boneka) }}=\underline{\text { 23,646 Jam }}=3,8$ atau 4 stasiun kerja

$$
\text { Ws } \quad 6,25 \mathrm{jam}
$$

Setelah melakukan perhitungan jumlah stasiun kerja, langkah selanjutnya adalah mengelompokkan elemen pekerjaan ke dalam stasiun kerja dengan menghitung total waktu dari elemen tersebut yang tidak melebihi waktu siklus. langkah selanjutnya pada metode ini yaitu menghitung lintasan efisiensi, smoothness index, delay time, presentasi waktu menganggur (\%DT) dan efisiensi stasiun kerja (ESK). Uraian pada masing-masing perhitungan adalah sebagai berikut:

$$
\text { 1. } \begin{aligned}
\mathrm{LE} & =\frac{\Sigma \mathrm{ST}}{\mathrm{K} \times \mathrm{CT}} \times 100 \% \\
& =\frac{1410,87}{4 \times 375} \times 100 \%=94,06 \%
\end{aligned}
$$

2. Minimasi Smoothness Index

$$
\begin{aligned}
\mathrm{SI} & =\sqrt{ } \Sigma(\mathrm{ST} \max -\mathrm{STI})^{2} \\
& =\sqrt{ }(374,47-374,47)^{2}+(374,47-364,2)^{2}+(374,47-346,9)^{2}+(374,47-325,3)^{2} \\
& =\sqrt{ }(0)^{2}+(10,27)^{2}+(27,57)^{2}+(49,17)^{2} \\
& =\sqrt{ } 3283,3 \\
& =57,3
\end{aligned}
$$


3. Delay Time (DT)

$\mathrm{DT}=\mathrm{k} \times \mathrm{ST} \max -\Sigma \mathrm{STI}=4 \times 374,47-1410,87=87,01$ menit

$$
\begin{aligned}
& \text { 4. Persentasi Waktu Menganggur (\%DT) } \\
& \begin{aligned}
\% \text { DT } & \frac{\text { DT }}{\mathrm{kx} \mathrm{ST} \max } \\
& =\frac{87,01}{4 \times 374,47} \\
& =5,80 \%
\end{aligned}
\end{aligned}
$$

5. Efisiensi Stasiun Kerja (ESK)

$$
\begin{aligned}
& \text { ESK } \mathrm{i}=\frac{\mathrm{ST} \mathrm{I}}{\mathrm{ST} \max } \times 100 \% \\
& \text { ESK } 1=\frac{374,47}{374,47} \times 100 \%=100 \% \quad \text { ESK } 3=\frac{346,9}{347,47} \quad X 100 \%=92,64 \\
& \text { ESK } 2=\frac{364,2}{374,47} \times 100 \%=97,26 \% \quad \text { ESK } 4=\frac{325,3}{374,47} \quad X 100 \%=86,87 \%
\end{aligned}
$$

Pada perhitungan Efisiensi stasiun kerja, rumus yang digunakan dapat dilihat pada perhitungan diatas, waktu ST didapat dari penjumlahan setiap masing-masing pekerjaan pada produksi rumah boneka dari produksi pembuatan pola hingga proses pengecatan. Penjumlahan waktu tersebut tidak boleh lebih dari waktu STmax. Penjumlahan waktu tersebut menggunakan satuan menit.

\section{Identifikasi Waste Pada Proses Produksi Rumah Boneka}

Berdasarkan pengamatan yang dilakukan di lantai produksi dapat dikemukakan aktivitas yang tidak perlu terjadi yang dapat memperpanjang lead time hal ini dapat mengakibatkan terlambatnya waktu produksi dan panjangnya lead time produksi rumah boneka tersebut. Panjangnya lead time dan waktu masing-masing stasiun kerja dapat dilihat pada Gambar 2.

Berdasarkan gambar tersebut selanjutnya dapat diidentifikasi kegiatan yang tidak memberi nilai tambah pada proses produksi, seperti: menunggu, mengambil bahan atau peralatan, melakukan proses ulang, memindahkan material dan sebagainya. Dan kegiatan yang memberikan nilai tambah seperti proses produksi dari masing-masing proses serta kegiatan yang tidak memberikan nilai tambah tetapi diperlukan pada produksi ini, seperti: mengukur dan inspeksi oleh bagian komite. Rekapitulasi persentasi Value Added (VA), Non Value Added (NVA) dan Non Value Added Necessary (NVAN) dapat dilihat pada Tabel 3.

Tabel 3. Rekapitulasi persentasi VA, NVAN dan NVA

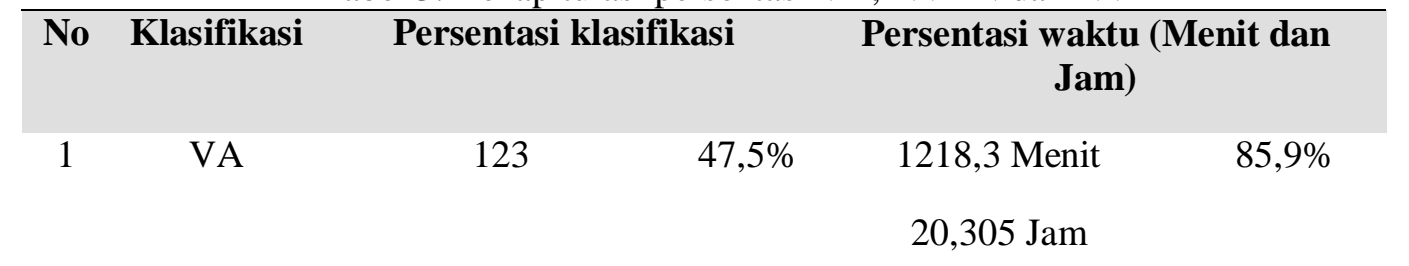




\begin{tabular}{|c|c|c|c|c|c|}
\hline \multirow[t]{2}{*}{2} & NVA & 42 & $16,2 \%$ & 166,61 Menit & $11,7 \%$ \\
\hline & & & & 2,77 Jam & \\
\hline \multirow[t]{4}{*}{3} & NVAN & 94 & $36,3 \%$ & 33,85 Menit & $2,4 \%$ \\
\hline & & & & 0,56 Jam & \\
\hline & Total & 259 & & 1418,76 Menit & \\
\hline & & & & 23,646 Jam & \\
\hline
\end{tabular}

Berdasarkan rekapitulasi persentasi pada Tabel 3 persentasi klasifikasi value added(VA), non value added (NVA), non value added necessary (NVAN), didapatlah hasil value added (VA) dari proses produksi rumah boneka sebanyak 123, non value added sebanyak 42 dan non value added necessary sebanyak 94 pekerjaan, maka total klasifikasi sebesar 259. Sedangkan untuk waktu total ketiga klasifikasi tersebut meliputi value added (VA) 1218,3 Menit atau 20,305 Jam, non value added (NVA) 166,61 menit atau 2,77 jam dan untuk non value added necessary (NVAN) 33,85 menit atau 0,56 jam. Berdasarkan ketiga kalsifikasi waktu tersebut maka didapatlah total waktu produksi rumah boneka 1418,76 menit atau dalam jam menjadi 23,646 jam.

\section{Perhitungan Value Added Ratio (VAR)}

Value added ratio adalah perbandingan atau persentasi antara value added time dengan non value added time (King, 2009). Rumus untuk menghitung value added ratio adalah sebagai berikut:

1. Pembuatan Pola

$$
\begin{aligned}
\mathrm{VAR} & =\frac{\mathrm{VA}}{\mathrm{NVA}+\mathrm{VA}} \times 100 \%= \\
& =\frac{126}{1,01+126} \times 100 \%=99 \%
\end{aligned}
$$

Dari hasil perhitungan pembuatan pola diatas, diketahui waktu NVA pada produksi rumah boneka sebesar 1,01 menit dan total waktu VA126 menit, dengan menggunakan rumus diatas maka didapatlah hasil perhitungan menjadi 99\%. Untuk hasil perhitungan value added ratio pada proses selanjutnya menggunakan rumus yang sama seperti diatas. Untuk hasil perhitungan masing-masing stasiun kerja dapat dilihat pada Tabel 4.

Tabel 4. Value Added Ratio

\begin{tabular}{ccccc}
\hline No & Stasiun kerja & $\begin{array}{c}\text { Total NVA Time } \\
\text { (Menit) }\end{array}$ & $\begin{array}{c}\text { Total VA Time } \\
\text { (Menit) }\end{array}$ & $\begin{array}{c}\text { Value Added } \\
\text { Ratio }(\%)\end{array}$ \\
\hline 1. & Pembuatan Pola & 1,01 & 126 & $99 \%$ \\
2. & Pemotongan Pola & 2,91 & 226 & $98 \%$ \\
3. & Pendempulan Pola & 3,2 & 117 & $97 \%$
\end{tabular}


Faktor Exacta 11 (3); 291-302, 2018

p-ISSN: 1979-276X

e- ISSN: 2502-339X

DOI : 10.30998/faktorexacta.v11i3.2685

Tiara - Pengurangan Pemborosan Waktu Produksi...

$\begin{array}{llll}5 . & \text { Perakitan } & 134,47 & 563,3\end{array}$

$\begin{array}{llll}\text { 6. Pengecatan } & 25,02 & 78 \%\end{array}$

(Ket: VA=Value Added, $\mathrm{NVA}=$ Non Value Added)

Perhitungan Takt Time

Perhitungan Takt Time menggunakan rumus dibawah ini, total waktu kerja normal adalah sebesar 2,5 jam atau sama dengan 150 menit. Target produksi perbulan yaitu sebesar 8 unit, sehingga perhitungan takt time adalah sebagai berikut:

Takt Time $=$ Available working time per day $=20$ hari $/ 8=2,5$ hari

Customer demand rate per day

\section{PENUTUP}

Simpulan

Berdasarkan pengolahan data dan analisis pada penelitian ini, maka dapat disimpulkan sebagai berikut : berdasarkan hasil pemetaan current state mapping, diketahui bahwa total processing time sebesar 1418,76 menit. Di lantai produksi CV.Rumah boneka terdapat pemborosan-pemborosan yang terjadi hal ini mengakibatkan panjangnya lead time produksi yaitu sebesar 10 hari. Pemborosanpemborosan tersebut yaitu pemindahan (transportation) bahan baku atau komponen-komponen dari rumah boneka yang akan digunakan pada produksi rumah boneka, gerakan (motion) mengambil dan mengembalikan alat ke tempat kerja yang letaknya berjauhan dari stasiun kerja sebelumnya, menunggu (waiting) komponen atau rumah boneka kering setelah proses pendempulan, perakitan dan pengecatan. Pemborosan selanjutnya yaitu pada kategori proses (processing), prosedur produksi dari proses perakitan kurang baik, mengakibatkan pekerja sering salah dalam melakukan aktivitas ini. Pemborosan terakhir yaitu persediaan (inventory) pada bahan baku paku.

Hasil identifikasi waste didapatkan bahwa aktivitas yang memiliki nilai tambah (value added/VA) sebesar 85,9\%, aktivitas yang dibutuhkan tetapi tidak memberikan nilai tambah (non value added necessary/NVAN) sebesar 2,4\% dan aktivitas yang tidak memberikan nilai tambah (non value added/NVA) sebesar 11,7\%.

Dengan menggunakan metode line balancing, dapat meratakan waktu siklus yang mengalami peningkatan atau waktu siklus yang berbeda sangat jauh pada masing-masing stasiun kerja. Hal ini dilakukan untuk menyeimbangkan lintasan produksi pada CV.Rumah boneka dengan menggabungkan elemen pekerjaan, sesuai dengan kapasitas waktu atau waktu proses pada masing-masing stasiun tidak melebihi waktu siklus. hal ini bertujuan agar proses produksi berjalan dengan lancar tanpa adanya kemacetan produksi.

\section{Saran}

Adapun saran untuk penelitian selanjutnya dianjurkan untuk menggambil data waktu produksi dari semua proses yang ada pada CV.Rumah boneka. Maka hasil yang didapat akan semakin baik, dan apabila ada perbaikan pada masing-masing proses maka akan diperbaiki bersama.

\section{DAFTAR PUSTAKA}


Faktor Exacta 11 (3): 291-302, 2018

p-ISSN: 1979-276X

e- ISSN: 2502-339X

DOI : 10.30998/faktorexacta.v11i3.2685

Tiara - Pengurangan Pemborosan Waktu Produksi...

Gasperz, V \& Fontana, A. (2011). Lean Six Sigma for Manufacturing and Service Industries. Bogor: Penerbit Vinchristo Publication.

Halim, A.H.(2003). TI-3122 perencanaan dan pengendalian Produksi: Keseimbangan Lintasan. Institut Teknologi Bandung. Retrieved from http://Istipb.org

Heizer, J. \& Render, B. (2009). Manajemen Operasi, Edisi 7. Jakarta: Salemba Empat

King, P. L. (2009). Lean for the Process Industries: Dealing with Complexity. CRC Press. Taylor \& Francis Group.

Nielsen, A. (2008). Getting Started with Value Stream Mapping. Salt Spring Island: Gardiner Nielsen Associates Inc. 